\title{
INTRODUCING THE METHODOLOGY OF TRANSPLANTING A NEW NATIONAL SPEED MANAGEMENT STRATEGY
}

\author{
Arpád Török \\ Department of Transport Technology and Economics \\ Budapest University of Technology and Economics \\ Budapest, Hungary, 1111 Budapest, Stoczek utca 2. building ST \\ 463-1061,artorok@kgazd.bme.hu
}

\begin{abstract}
This paper explains the most important methodological steps of introducing a new speed management strategy. The development of a speed monitoring system with a long term effect on the progress of road safety, makes it necessary to identify its strategic goals, main functions and system components. The strategy should investigate current speed management methods, regulation framework of road signs, tendencies represented by statistics, enforcement campaigns, control equipment, and last but not least the penalty system. Assessment of the applied speed enforcement practices and framework should involve the revision of the recently operating institutional, legal and technical framework of speed enforcement structure.
\end{abstract}

Keywords: speed management startegy, startegy adaptation, road safety, startegic element

\section{Introduction}

The aim of the article is to introduce the research carried out by author focusing on an efficient speed management strategy adaptation methodology considering international and national research results. Assessment of the applied speed enforcement practices and framework should involve the revision of the recently operating institutional, legal and technical framework of speed enforcement structure considering the most innovative and up to date technological development orientation. The suggested research process is based on the results of the latest referring national research study (KTI, 2016). In addition, certain speed related engineering regulations, prescriptions and national standards should be reviewed and a comprehensive overview of speed-related national training and education material should also be carried out in the frame of strategy development and implementation especially considering e-learning, online learning and interactive training possibilities to ensure the required scientific background of the national training system. It is also important to consider that the national speed strategy should take into account the results of the previously carried out national researches and beside of this the most innovative solutions of the recent years. To ensure that the speed management strategy involve the most innovative available technological elements it is important to invite companies to cooperate from telecommunication, information technology and intelligent transport system technology sectors (Lyons and Davidson 2016).

The implementation of a proper data collection system is also a crucial pillar of the speed management system. Accident data, its collecting process, speed data and speed monitoring system provides robust bases for awareness raising campaigns, prevention and enforcement activities which are important pillars of sustainable safety progress.

Another relevant part of speed management is enforcement. To evaluate this field and this part of the holistic system it is unavoidable to cooperate with national and international enforcement organizations to get acquainted with the most up-to-date methodologies. The most important requirement for speed enforcement is that it deters drivers from speeding; not only those drivers that have been apprehended for a speeding violation, but even more so, those who have not. This is called general deterrence. General deterrence is closely related to the risk of being caught as subjectively perceived by a driver. This subjective risk of apprehension can not only be increased by stepping up the intensity of actual speed enforcement, but also by making sure that, independent of the exact enforcement method, the speed enforcement activities are well-publicised, unpredictable and unavoidable, and sustained over a longer period of time. Furthermore, for a maximum effect, it is advisable to focus the speed enforcement operations on roads, situations, and times where speeding is considered to have the largest effect on the road safety level. Ideally, the enforcement operations are based on a thorough analysis of crashes and the role of speeding therein. Speed enforcement can be more effective if it is implemented on prioritised 
roads, in frequently periods. Beside of this, to define the adequately watchful speed enforcement strategy it is important to involve wide range of scientific groups from social fields like scientific institutes, associations, civil organizations and other transport related sectorial elements.

\section{Revision of the Current Speed Management Methods}

The first step of the revision process is the reviewing of the structure of the institutional background, especially supporting the "anywhere, anytime approach" in accordance with UN methodology (GRSP, 2008) focusing on strengthening specific and general deterrence. To achieve the objectives defined above, it is necessary to implement the following steps: 1) defining and implementing a pre-defined, minimum number of highly visible speed control activities based on an ex-ante evaluation; 2) defining and implementing a pre-defined, minimum number of covered speed controls based on an exante evaluation; 3 ) defining the location of the above-mentioned speed control activities based on a spatial probability model. This process model is the result of the referring national study which has underpin the assumption that efficient enforcement system depends on three main model variables: available resources, number of control, location of control (KTI, 2016).

In the next stage of the investigation the structure of the legal background has to reviewed, especially supporting "evidential requirements" in accordance with the UN methodology (GRSP, 2008) ensuring equal legal conditions for every road user. To achieve the above mentioned objectives the following legal conditions have to be supported by the related regulation framework: 1) evidence of the speed limit; 2) verifiable evidence of the speed alleged, including visual observations; 3) the type of equipment used; 4) the fact that the equipment was certified as accurate (by a secondary speed measurement device verified periodically); 5) any explanation offered by the driver (not essential); 6) environmental conditions e.g. traffic, weather and road conditions (relevant although not essential). Beside this it is also a crucial legal issue to review the hierarchy of roads by function, which reflects actual road operating activity, will provide the starting point for review and development of a speed limit framework.

It is also crucial a part of the revision process to review the current national speed control and measurement system, especially considering the technical requirements of an up-to-date speed management methodology in accordance with national (Automatic Speed Control Equipment) and international (ACPO, 2011) best practices. The intensification of enforcement and penalties can be achieved through introduction of automatic enforcement and penalty systems for speed violations. The higher automation level the speed enforcement system has, the stronger deterring effect it can have, hence the improvement of the level of system automation is a key issue of this activity. To develop this part of the concept it is crucial to involve organizations form the field of information technology and telecommunication to ensure the appearance of the most up-to-date and innovative technology in the strategy.

Beyond structural revision process components it is also a relevant part of the analysis to define technical requirements and standards for manual and automated camera enforcement of speed limits in accordance with the recommendations of GRSP (2008): reliability, accuracy, image quality, maintenance questions, cooperability with driver licensing and vehicle registration, postal and jurisdiction system, data capturing technical requirements, effective back-office processing system, issue of infringement notice and follow up procedures for collection of unpaid fines from defaulters, preventing vandalism. It is also very important to invite institutions form the field of intelligent transport systems and telecommunication to provide the involvement of the most up-to-date and innovative methodologies and techniques in the strategy.

Beside legal, institutional, and technical environment of the existing enforcement system it is also an elementary component of the revision process to investigate existing national road design and traffic engineering regulations and directives to adapt the most important safety principles - such as selfexplaining and forgiving road design approaches - during the planning process of road infrastructures' speed conditions; especially considering parameters concerning lane width, curve radius, visibility; centre island, raised median, speed hump, facilities for pedestrians and vulnerable road users, roundabouts and gate-way treatments considering the most relevant international best-practices and recommendations (NHTSA, 2009; 2012).

A complementary element of the review task is to reconsider the structure and content of speedrelated official safety education and training materials based on target group classification based on accident statistics. As in the case of other data-based activities, it is crucial here to have an accident 
database as reliable and accurate as possible, since accident data collection systems and processes have a pivotal importance in safety and speed management-related decision support processes.

The final step of the revision process is to review, or, if necessary, develop a speed management strategy. A Speed Management Strategy addresses the concern of unlawful and undesirable speeds within a road network. The program should be comprehensive, addressing all factors that influence speeding: public awareness, user behaviour, roadway design, surrounding land uses, traffic conditions, posted speed limits, and enforcement.

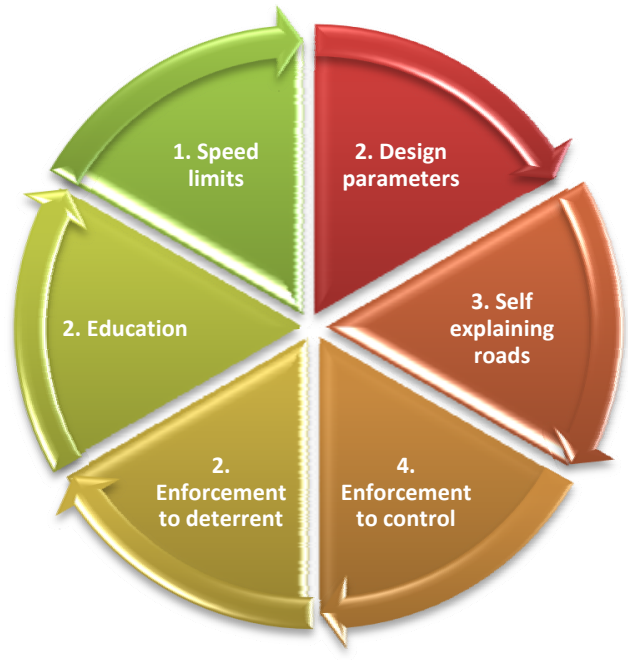

Figure 1. The proposed speed management

Therefore, the program should encompass engineering, enforcement, and education. Engineering is used to accomplish the following: 1) establishing speed limits that are appropriate to the primary purpose of the road, provide a balance between mobility and safety for all roadway users, and meet all state or local legal requirements; 2) designing roads that produce desired speeds; 3) introducing physical countermeasures to create a self-explaining roadway that induces drivers to travel at the desired speed; 4) implement enforcement process encompassing the actions taken by appropriate empowered authorities to check that drivers of motor vehicles are complying with the legal posted speed limit; 5) various countermeasures being used by law enforcement to deter drivers from speeding; 6) education providing information to drivers about their travel speeds and safety issues associated with speeding and to heighten their awareness of enforcement countermeasures that are designed to curtail speeding (GRSP, 2008; SafetyNet, 2009). It is inevitable to cooperate with partners dealing with technological engineering to implement the as innovative solutions as the available resources.

\section{Speed Limit Signs}

In the next stage of the strategy formulation it seems to be crucial to define the required processes and their relations in the field of the technical parameters of static traffic signing methods. The main relationships of the basic process element can be presented by the intervention pyramid (KTI, 2016). The largest diversity of possible interventions is given in the field of choosing speed limit, road environment is more or less determined, there probability space of changing the environment is much tighter than the previously mentioned group. The narrowest set of possibilities is given in the field of the practical installation of signs, since this field is strictly regulated by the referring national and international standards. The revision of the regulation framework in regard to speed limit signs and the related operating processes is a key issue to improve traffic safety. Relevant national regulation framework focusing on speed limit signs significantly determines road safety situation in a country especially considering national standards discussing visibility and perceptibility, standards concerning speed limit signage including sight distance considerations as well. This process begins with the most important basic legal documents - such as the traffic code - and ends with the corresponding technical standards. In addition to background evaluations, practical issues are equally important, such as: speed limits must be marked clearly and visibly in accordance with relevant professional best practices so that drivers can never be in any doubt regarding the prevailing limit. As a result, operational processes need to be 
reviewed as well. Since most of the countries have joined to UN Convention on Road Traffic (Vienna, 8 November 1968), road signs have to be installed in accordance with the international standards.

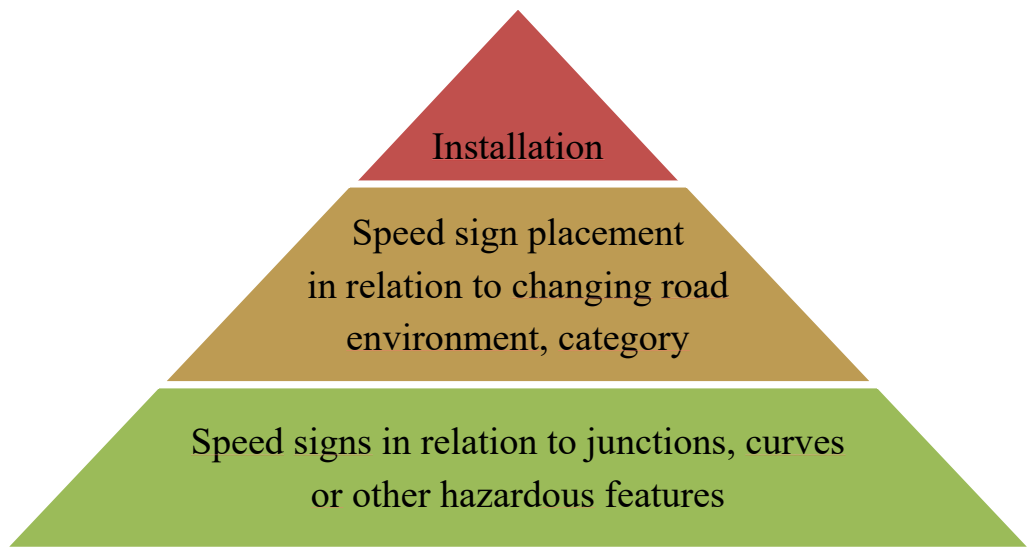

Figure 2. Revision of road sign related regulation framework

These requirements makes it necessary to review the national technical regulations referring to the installation of signs and signals in the following steps: 1) controlling national regulations discussing speed signs' siting along the road in relation to the junction, hazard, or other feature to which it applies; 2) controlling national regulations discussing speed signs' placement in relation to changing road category (e.g. the edge of the carriageway and other features of the cross section) and 3) controlling national regulations discussing speed signs' installation (e.g. height above the road) (Elvik et al., 1997; Mocsári, 2012).

After the analysis of the related frame work the next step is to review standards and technical regulations which concern speed limit signage - including indicating infrastructure components with hazardous design parameters or raised accident probability e.g. sharp curves or declines - has a crucial role in the revision process (2008/96/EC, 2008).

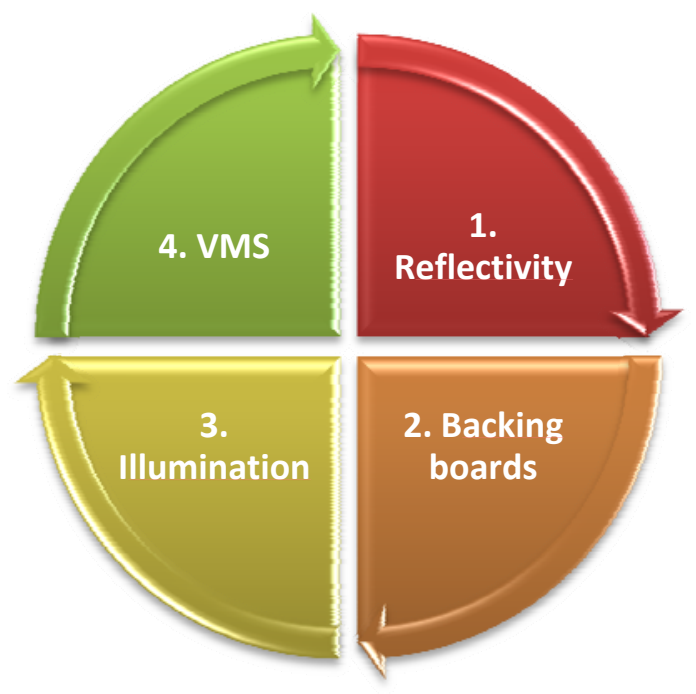

Figure 3. Revision of road sign related technical regulations

This activity is composed by the following steps in accordance with the best practices of the leading European countries in road safety (Elvik et al., 1997; GRSP, 2008; Mocsári, 2012): 1) reviewing standards focusing on reflectivity to ensure conditions for adequate visibility; 2) reviewing standards focusing on backing boards to improve contrast against a complex or dark background; 3) reviewing standards focusing on illumination to enhance visibility especially in low-light conditions; 4) reviewing standards focusing on variable message signs (VMS) to clarify the technical requirements of installation (FHWA, 2003). 
Following this, standards and technical regulations concerning speed limit signage related to tunnels should be reviewed especially in countries where due to the mountainous terrain, tunnels play an important role in transportation. Since the accident risk of tunnels is higher than that of the average road infrastructure elements, the objective of this process class is to review the corresponding technical standards, focusing on their ability to compensate for the increased risk, especially considering low-light conditions and the effects of monotony.

Although the literature does particularly not discuss decision making processes related to speed management, however it is crucial from a sustainability point of view to allocate available national resources efficiently. In accordance with the sustainability aspect, the expected costs and savings of the speed management intervention shall be compared based on internal and external impacts, especially considering investment costs, operational costs, savings and costs related accidents, time, noise and pollution during the decision-making process.

Although the adaptation of common speed management standards referring to the most up-to-date infrastructure solutions (e.g. turbo roundabout, etc.) is also not a frequently investigated research field it is an important step of preparing a comprehensive speed management strategy and increasingly important from road safety aspects, hence the revision of standards and technical regulations discussing the details of speed limits at specific types of infrastructure elements is also an important milestone of the transplantation process.

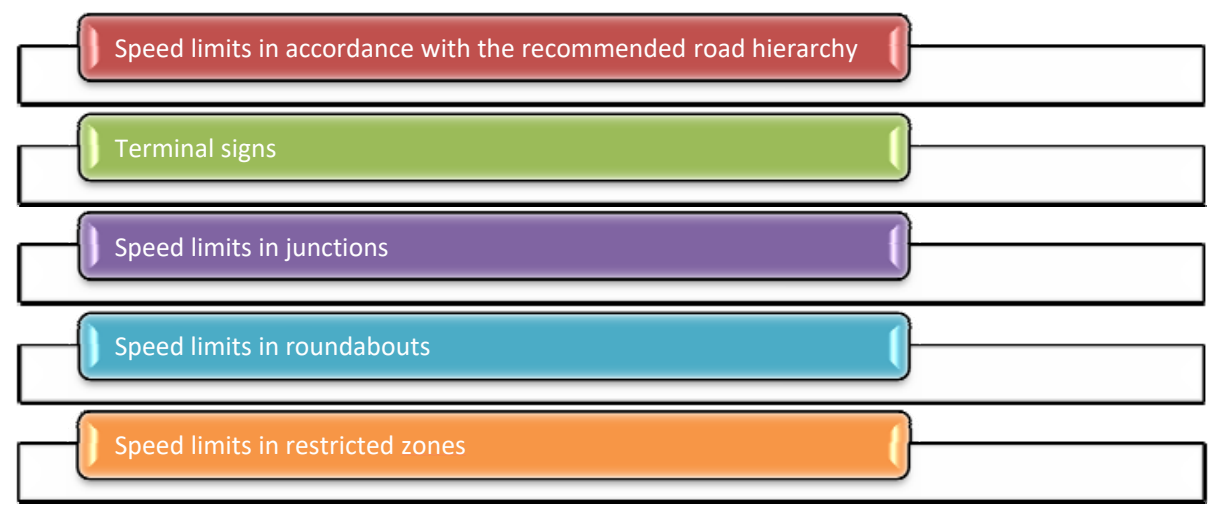

Figure 4. Speed limits at specific types of infrastructure elements

Therefore, the review process should include the following topics: 1) national speed limits in accordance with the recommended road hierarchy; 2) terminal signs indicating maximum speed limits especially considering the presence or the lack of a traffic island; 3) maximum speed limits in junctions; 4) maximum speed limits in roundabouts and 5) zones with restricted speed limits, traffic calming.

Similarly to the previously discussed complementary strategic component, the revision of the "speed management standards based on a complex network approach" is also a crucial pillar of the holistic approach. The reason of this is that the presence of a network approach and the complex coherence of speed management is a key issue of road safety getting more and more important. The network approach-based speed management standard environment (e.g. pre-indication of speed limits, the necessary amount of steps in speed limit reduction) has to take into account local social and cultural characteristics, especially considering such processes which play a key role in society (Tötök and Zefreh, 2016), such as trends in compliance, risk compensation characteristics, ageing society, the role of car ownership and speed choice in social relations and in individual self-identification.

\section{Accident Statistics and Road Sections with Higher Speed Data}

The scientific filed of accident statistics analysis and its correlation of road parameters is soundly researched and investigated area, hence efficient and innovative methodologies is easily available (Holló et al., 2010; Wegman et al., 2005). The first step to implement a comprehensive analysis focusing on the identification of road sections with excessive speeds history - is to evaluate the spatial distribution of historical speed data in order to identify sections and cross-sections characterised by persistently high v85 speed data. To do this, it is indispensable to have spatially identified historical speed data. If the required data is not available, it is necessary to carry out speed measurements collecting v85 data for the chosen 
locations in order to provide the necessary input dataset. This requires implementing a representative network of measurement locations. This activity contributes to handling local speed-related problems (Elvik et al., 1997).

Beside local problems, beyond the identification of the locations most affected by speeding, it is also a key issue from a road safety point of view to analyse the ratio of accidents caused by speeding compared to other causes. This contributes to understanding social processes behind the statistics in order to identify social groups mostly affected by accidents related to inappropriate speed choice. The results should be compared to the statistics of other European countries which would allow us to determine the most important target areas. This could be done by using the databases of road safety related international organizations such as IRTAD or CARE (GRSP, 2008).

It is also an important part of the investigation to combine the results of the previously carried out analysis, which means that - based on available accident data and the data concerning sections with excessive speeds - it is necessary to identify sections and cross-sections highly affected by accidents caused by speeding by analysing the spatial distribution of related accident data (Geurts and Wets, 2003).

We should also not forget the problem of data collection, since a consistent data collection system is crucial to provide the ability of the safety system to forecast unfavourable social and economic trends adversely affecting the road safety situation. Accurate and reliable accident data can ensure robust basis for a continuous and sustainable reduction in the number of accidents.

In addition to an accident data collection system, the speed monitoring system also needs to be reviewed and if necessary implemented. A well-structured speed monitoring system is indispensable in following road safety processes on a national level. In accordance with this approach, speed is an important safety performance indicator in selecting the best-performing countries, giving a comprehensive picture about national safety trends.

\section{Enforcement Campaigns}

In order to support or develop speed enforcement campaigns - in accordance with the recommendations of Speed Management guidebook of the European SafetyNet project (SafetyNet, 2009) and U.S. Department of Transport (NHTSA, 2007) - it is a fundamental methodological step to identify the target groups of the campaign. The reasonable identification of target groups can ensure the expected efficient communication effect of the project. From a road safety point of view, campaigns should focus on road user groups that are the most affected by speeding-related accidents (e.g. young drivers, transit traffic, tourists, elderly drivers, professional drivers, etc.) (Jankowska et al., 2015). The identification of target groups can be based on accident data analysis, or the evaluation of other social trends and processes (e.g. supporting vulnerable road users or public transport, controlling transit traffic in villages).

The next step of supporting a speed enforcement campaign is the selection of control locations for enforcement. From the awareness raising point of view, enforcement targeting a limited number of highrisk violations characterised by higher traffic volumes and wide publicity is more effective in reducing road crashes than non-targeted general enforcement.

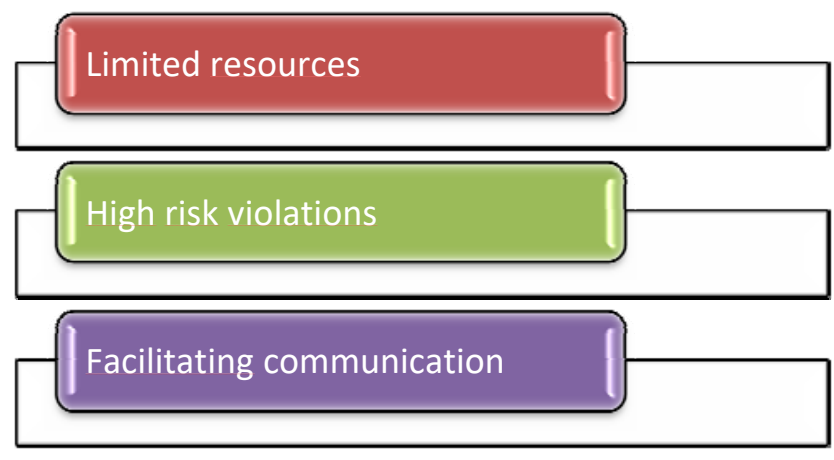

Figure 5. Reasons of selecting a limited number of high-risk violations

There are various reasons: 1. Given the limited manpower and equipment of the police service, enforcement will always aim to get maximum value from scarce resources. 2. Focusing on one or more high-risk violations such as speeding is also justifiable given the scientific evidence of the relationships 
between level of speed and road safety risk. 3. It is easier to communicate to road users about a limited and specific number of violations than about traffic violations in general.

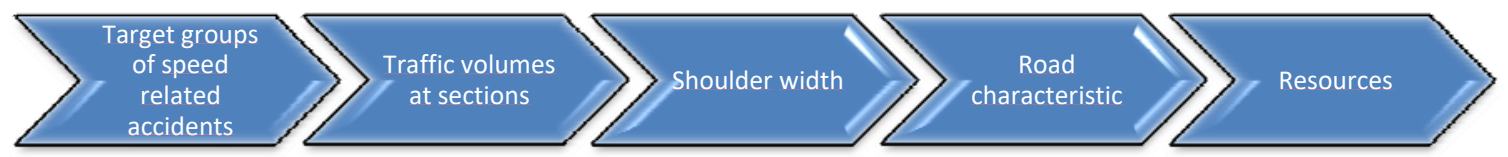

Figure 6. Main factors of selecting enforcement locations

In accordance with the above identified objectives there are five main factors which should be considered during the selection of enforcement locations (Nilson, 2004; Elvik et al., 1997): 1) spatial distribution of the target group's speed-related accidents; 2) traffic volumes, visibility, publicity and communication possibilities on the road network; 3) shoulder width on the road network (shoulders must be wide enough to make a safe traffic stop); 4) Road characteristics and conditions, such as the number of lanes and planned construction projects; 5) available human resources / police force.

In accordance with the methodology recommended by the UN (GRSP, 2008), the final task after selecting target groups and locations is to define a time period and schedule for program implementation.

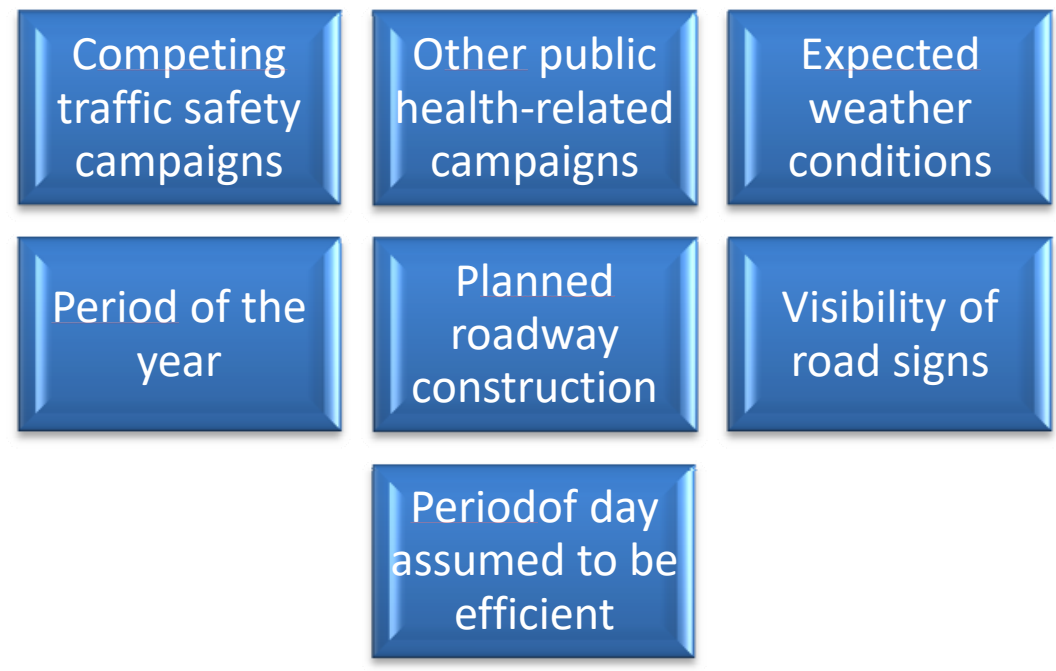

Figure 7. Factors of program schedule

When defining the schedule for program implementation, the following factors should be considered: 1) competing traffic safety campaigns; 2) other public health-related campaigns or local events that will compete for media attention; 3) expected weather conditions; 4) time of the year (e.g. holidays); 5) planned roadway construction or maintenance; 6) the visibility of road signs; 7) time of day assumed to be efficient, considering the targeted road user groups' mobility habits (e.g. peak hours, night, etc.).

\section{Equipment}

To develop a speed monitoring system which has long term effects on the progress of road safety, it is essential to identify its strategic goals, main functions and system components.

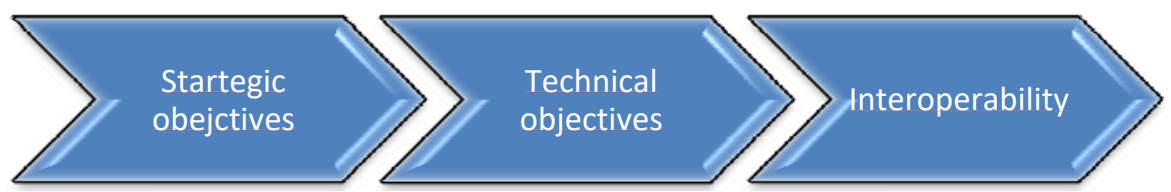

Figure 8. Main aspects of system concept

Therefore: 1) the system concept has to identify the main objectives such as increasing the risk of violators being prosecuted, continuous and visible enforcement presence to increase compliance and 
supporting enforcement campaigns to increase the deterrent effect of enforcement; 2) the concept also has to clarify the most important objectives of the system such as recording traffic speeding, recording other traffic violations, recording and indicating accidents, indicating special traffic disruptions, or indicating extreme weather conditions; 3) last but not least, the concept needs to introduce connecting cooperative systems such as official vehicle and driving licence database, emergency and rescue services, disaster recovery systems, or toll collection systems (ACPO 2011; NHTSA, 2013). Based on international best practices (ACPO 2011; NHTSA, 2013), the next step of this activity is to define the modular structure of the speed monitoring system, especially considering its most important components and their specifications.

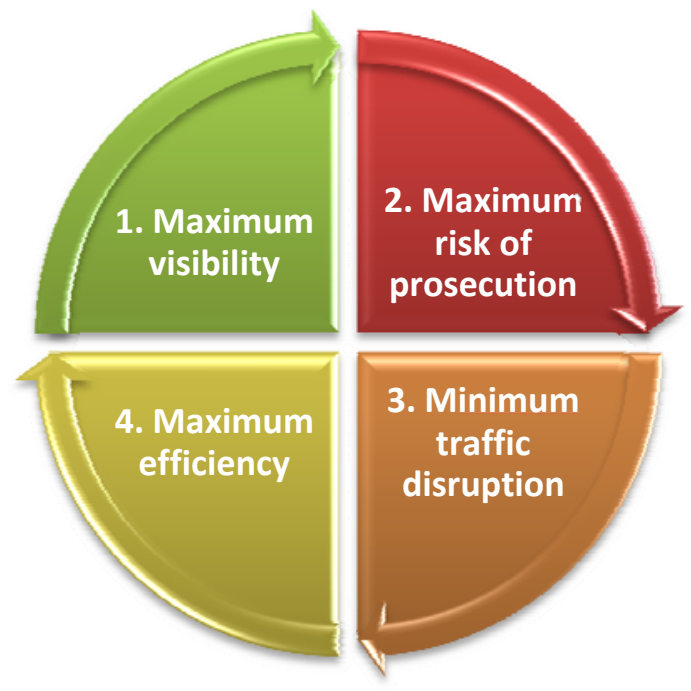

Figure 9. Main system objectives

Considering available resources and the main system objectives, the modular structure should reflect to and find the balance between the following competing issues: 1) maximizing visibility; 2) maximizing the risk of prosecution; 3) minimizing traffic disruption; 4) maximizing efficiency (cost per tracked non-compliant driver). Considering the above, an optimal system should be constructed from the following components: 1) patrol vehicles fitted with speed cameras; 2) hand-held radar speed cameras (it should be noted that the vehicle needs to be tracked with the aiming sight to allow the instrument to make a satisfactory speed measurement); 3) traffic enforcement cameras mounted over roadways or portable devices (supervised automatic or attended actively operated), it should be noted that these types of radars have a fixed radar device that projects a radar beam across the road at a fixed angle (to avoid cosine effect); 4) parabolic radar - mounted over roadways, the beam is used to illuminate a specific section of road, typically one lane from suspended equipment, coupled with a speed camera; 5) laser speed cameras - this instrument type projects a laser beam at target vehicles in a way that illuminates reflective parts of the vehicle, by using a series of light pulses, the device can calculate the speed of the target vehicle. It should be noted that laser detectors are typically used hand-held or mounted on a tripod, all of which must be actively operated; 6) cameras - these devices are responsible for providing evidence, records and section control.

To implement the speed monitoring system, it is necessary to define a detailed system specification concerning the required technical conditions of the system components. In accordance with relevant technical standards, in addition to costs, the equipment also has to be evaluated based on the most important technical aspects such as (Török et al., 2014): 1. Range Accuracy; 2. Long Range; 3. Beam Characteristics; 4. Environmental Extremes; 5. Low Voltage Indicator; 6. Supply Voltage Tolerance; 7. Speed Display; 8. Speed Accuracy: Laboratory Simulation; 9. Conducted Electromagnetic Interference; 10. Radiated Electromagnetic Interference; 11. Speed Accuracy: Field Operation; 12. Vehicle or text determination.

\section{Penalty System}

To analyse the penalty system in accordance with international experiences, the first step is to identify the expected road safety impact, the available budget and resources, the expected social 
acceptance of the intervention, compliance, revenue objectives and public initiatives expected to be financed from penalty revenue. To do this, it is crucial to evaluate international best practices, especially considering the relationships between penalties, social acceptance and penalty revenue in the investigated countries (IRF, 2016).

Considering the identified competitive penalty system factors, it is necessary to define the level of public and/or private contribution in implementation. In accordance with international best practices, cost effectiveness and social benefits should be considered (e.g. private systems could shift into the direction of profit maximization instead of minimizing negative safety effects, while public systems may be characterized by low operational efficiency).

The final step is to review the transparency of the distribution processes between penalty revenue and re-investment components. The transparency of the penalty system should be thoroughly planned and implemented, this can significantly improve social acceptance and can support financial planning and feasibility (Wijers, 2016).

\section{Summary}

The first step of speed management strategy implementation process is to review the structure of the institutional background, especially supporting the "anywhere, anytime approach" in accordance with UN methodology (GRSP, 2008) focusing on strengthening specific and general deterrence. To achieve the objectives defined above, it is necessary to implement the following steps: 1) defining and implementing a pre-defined, minimum number of highly visible speed control activities based on an exante evaluation; 2) defining and implementing a pre-defined, minimum number of covered speed controls based on an ex-ante evaluation; 3) defining the location of the above-mentioned speed control activities based on a spatial probability model.

The next step of the investigation is to implement a comprehensive analysis focusing on the identification of road sections with excessive speeds history - is to evaluate the spatial distribution of historical speed data in order to identify sections and cross-sections characterised by persistently high v85 speed data (Mocsári, 2012).

It is also a relevant component of the speed management system to support or develop speed enforcement campaigns - in accordance with the recommendations of Speed Management guidebook of the European SafetyNet project and U.S. Department of Transport - it is a fundamental methodological step to identify the target groups of the campaign. The reasonable identification of target groups can ensure the expected efficient communication effect of the project.

To implement a speed monitoring system, it also is necessary to define a detailed system specification concerning the required technical conditions of the system components.

Finally we should not forget about a main system component which is the penalty system. The planning process of a comprehensive penalty system should involve the aspects of the expected road safety impact, the available budget and resources, the expected social acceptance of the intervention, compliance, revenue objectives and public initiatives expected to be financed from penalty revenue.

Summing up we can state that the development of a speed monitoring system with a long term effect on the progress of road safety, makes it necessary to identify its strategic goals, main functions and system components.

\section{References}

1. 2008/96/EC (2008) Directive 2008/96/EC of the European Parliament and of the Council of 19 November 2008 on road infrastructure safety management.

2. ACPO - Association of Chief Police Officers of England, Wales and Northern Ireland (2011) Guide for the Operational Use of Speed and Red-light Offence Detection Technology.

3. Elvik, R., Mysen, A.B. and Vaa, T. (1997) Trafikksikkerhetshåndbok. Transportøkonomisk institut (TØI), Oslo, Norway. (In English: Traffic handbook).

4. FHWA - Federal Highway Administration Office of Safety (2003) Updated Minimum Retro reflectivity Levels for Traffic Signs.

5. Geurts, K. and Wets, G. (2003) Black Spot Analysis Methods: Literature Review. Limburgs Universitair Centrum.

6. GRSP - Global Road Safety Partnership (2008) Speed management. A Road Safety Manual for Decision-makers and Practitioners. 
7. Holló, P., Vojtech E., Zukowska J. (2010) Road safety performance indicators and their explanatory value: A critical view based on the experience of Central European countries. Safety science 48.9 (2010): 1142-1150.

8. IRF - International Road Federation (2016) Public Private Partnerships in Traffic Enforcement. $A$ White Paper from the International Road Federation.

9. Jankowska, D., Mikušová, M., Wacowska-Ślęzak, J. (2015) Mobility Issues in Selected Regions of Poland and Slovakia - Outcomes of International Project SOL (Save Our Lives) Survey, Period. Polytech. Transp. Eng., Vol. 43, No. 2 (2015), pp. 67-72., DOI: 10.3311/PPtr.7580

10. KTI - Institute for Transport Sciences (2016) Road Safety Development Techniques in Urban and Rural Environment. Research Study.

11. Lyons, G. and Davidson, C. (2016) Guidance for transport planning and policymaking in the face of an uncertain future. Transportation Research Part A: Policy and Practice, 88, 104-116.

12. Mocsári, T. (2012) A gépjármüvek sebességének hatása a közúti közlekedés biztonságára. Széchenyi István Egyetem, Müszaki Tudományi Kar. (In English: The Effect of Traffic Speed on Road Safety).

13. Nilsson, G. (2004) Traffic safety dimensions and the power model to describe the effect of speed on safety. Bulletin-Lunds Tekniska Högskola, Inst för Teknik och Samhälle, Lunds Universitet, 221.

14. SafetyNet (2009) Speed Enforcement Report http://ec.europa.eu/transport/road_safety/specialist/knowledge/pdf/speed_enforcement.pdf

15. Török, A. and Zefreh, M.M. (2016) Assessing the Need for Applying Multimodal Speed Distribution in Road Transport Macro Emission Estimation. Acta Technica Jaurinensis, 9(2), 118127.

16. Török, Ár. and Török, Ád. (2014) Macroeconomic analysis of road vehicles related environmental pollution in Hungary. Central European Journal of Engineering, 4(2), 186-191.

17. U.S. Department for Transportation - National Highway Traffic Safety Administration (NHTSA) (2007) Guidelines for Developing a High-Visibility Enforcement Campaign to Reduce Unsafe Driving - Behaviours among Drivers of Passenger and Commercial Motor Vehicles.

18. U.S. Department for Transportation - National Highway Traffic Safety Administration (NHTSA) (2009) Speed Concepts: Informational Guide.

19. U.S. Department for Transportation - National Highway Traffic Safety Administration (NHTSA) (2012) Speed Management A Manual for Local Rural Road Owners.

20. U.S. Department for Transportation - National Highway Traffic Safety Administration (NHTSA) (2013) LIDAR Speed-Measuring Device Performance Specifications.

21. Wegman, F., Eksler, V., Hayes, S., Lynam, D., Morsink, P. and Oppe, S. (Eds.) (2005) SUNflower+ 6. A Comparative Study of the Development of Road Safety in.

22. Wijers, P.J (2016) Public Private Partnerships for Traffic Enforcement based on the IRF 'Statement of Policy'. International UNECE PPP Forum 30 March - 1 April 2016 Palais des Nations Geneva.

23. Zefreh, M.M. and Török, Á. (2016) Improving Traffic Flow Characteristics by Suppressing Shared Taxis Maneuvers, Period. Polytech. Transp. Eng., Vol. 44, No. 2 (2016), pp. 69-74., DOI: 10.3311/PPtr.8226 